\title{
NITOGEN INPUTS REDUCE FUNGAL DIVERSITY AND ALTER COMMUNITY COMPOSITION IN A CHINESE FIR PLANTATION
}

\author{
GAO, X. H. ${ }^{2}-$ FAN, P. S. ${ }^{1}-$ WANG, J. L. ${ }^{3}-$ RUAN, Y. Z. ${ }^{1}-$ WANG, Q. ${ }^{*}$ \\ ${ }^{1}$ Hainan Key Laboratory for Sustainable Utilization of Tropical Bio-resources, College of \\ Tropical Crops, Hainan University, Haikou 570228, China \\ ${ }^{2}$ Institute of Bioengineering, Guangdong Academy of Sciences, Guangzhou 510316, China \\ ${ }^{3}$ National Engineering Laboratory of Biohydrometallurgy, GRINM Resources and Environment \\ Tech. Co., Ltd, Beijing 100088, China \\ ${ }^{*}$ Corresponding author \\ e-mail: wangqing316000@163.com
}

(Received $1^{\text {st }}$ Feb 2021; accepted $14^{\text {th }}$ May 2021)

\begin{abstract}
Soil fungi are pivotal drivers of nutrient cycling in forest ecosystems. Nitrogen $(\mathrm{N})$ input is projected to increase with global climate change, but the effect of $\mathrm{N}$ addition on fungal diversity and community composition in subtropical forests remains unclear. Here, we used high-throughput sequencing of the ITS region to quantify the changes in fungal diversity and community composition in response to an eight years of simulated $\mathrm{N}$ addition in subtropical forest ecosystems. Soil nutrient concentrations $\left(\mathrm{NH}_{4}{ }^{+}\right.$, $\mathrm{NO}_{3}{ }^{-}$, dissolved organic carbon (DOC), and Total $\mathrm{N}$ ) increased, but $\mathrm{pH}$ and fungal alpha diversity decreased with $\mathrm{N}$ addition compared to control treatments. Ascomycota and Zygomycota were stimulated by $\mathrm{N}$ addition, while Basidiomycota decreased. Principal coordinates analysis showed that fungal community composition in the control treatment was significantly different from various $\mathrm{N}$ addition treatments. $\mathrm{N}$ additions increased available $\mathrm{N}$ concentrations which overwhelmed other factors and played a key role in decreasing fungal diversity and skewing community composition. Thus, simulated $\mathrm{N}$ deposition reduced fungal biodiversity and altered fungal community composition, likely mediated via changes in available nutrients in the soil.
\end{abstract}

Keywords: high-throughput sequencing, soil microbial ecology, $N$ addition, soil properties

\section{Introduction}

Anthropogenic activities have elevated reactive nitrogen $(\mathrm{N})$ deposition in terrestrial ecosystems since the Industrial Revolution through fossil fuel combustion and widespread use of N-rich fertilizers (Galloway et al., 2008; Canfield et al., 2010). Atmospheric N deposition has increased 3 to 5 -fold over the past century, and the mean $\mathrm{N}$ deposition rate is expected to continue rising up to $250 \%$ in the near future (Galloway et al., 2008; IPCC, 2017). Excessive $\mathrm{N}$ inputs could result in many adverse ecological effects on terrestrial ecosystems, including soil acidification (Lu et al., 2014), nutrient imbalance (Lu et al., 2010), and increased nitrous oxide $\left(\mathrm{N}_{2} \mathrm{O}\right)$ emission (IPCC, 2007). Numerous studies have extensively documented the effects of $\mathrm{N}$ addition on aboveground plant communities and soil nutrient cycles (Hooper et al., 2012; Isbell et al., 2013). However, the response of belowground soil microorganisms, such as the fungal community, to $\mathrm{N}$ additions in subtropical forests remains unclear (Wei et al., 2018; Ma et al., 2019).

Soil microorganisms are directly related to soil biogeochemical processes and play an important role in nutrient cycling (Morris and Blackwood, 2015). Fungi significantly affect ecosystem structure and function and are key components of soil microbial communities with multiple functions, such as organic matter decomposition, nutrients for plants, and 
pathology (Altieri, 1999; Aguilar-Trigueros et al., 2014). A large body of research about the impacts of nutrients inputs on fungal communities has been reported (Fierer et al., 2012; He et al., 2016; Zhou et al., 2016; Li et al., 2019; Zhao et al., 2020); however, the results of these studies are varied and inconsistent. Some have shown that $\mathrm{N}$ fertilization elevates fungal abundance (Zhou et al., 2016; Wang et al., 2018b) and decreases alpha diversity in arable soil (Zhou et al., 2016). Other studies have revealed that $\mathrm{N}$ inputs increased fungal alpha diversity in a mixed deciduous forest (Zhao et al., 2020). Recently, Li et al. (2019) reported that $\mathrm{N}$ and $\mathrm{P}$ additions had no effect on fungal alpha diversity and community structure in a subtropical forest. Simultaneously, the previous studies also investigated the correlation between fungal community composition and abiotic factors including $\mathrm{pH}$, water content, nutrient availability, and plant diversity, but the results are inconsistent across different ecosystems (Zhou et al., 2016; Li et al., 2019; Zhao et al., 2020). Thus, more empirical research is needed to understand the underlying mechanisms of $\mathrm{N}$ additions on fungal community structure in forest ecosystem.

The Chinese fir (Cunninghamia lanceolata) is widely planted in south China due to its high economic value, and fertilization is believed to be the most effective and feasible method to increase its productivity. Thus, we designed a simulated $\mathrm{N}$ addition field trial in 2011 in a subtropical forest in the Qianyanzhou Experimental Station, Jiangxi, China. Our objectives were to (1) quantify soil fungal diversity and community composition following the input of different amounts of $\mathrm{N}$ fertilizer and (2) identify the primary soil factors driving the fungal community.

\section{Materials and Methods}

\section{Site description and experimental design}

The experiment was conducted in a rehabilitated secondary forest at an elevation of $102 \mathrm{~m}$ above sea level in the Qianyanzhou Forest Experimental Station, Jiangxi, China $\left(26^{\circ} 44^{\prime} 52^{\prime \prime} \mathrm{N}, 115^{\circ} 04^{\prime} 13^{\prime \prime} \mathrm{E}\right)$, which is a typical subtropical agricultural region. The average annual precipitation is $1471.2 \mathrm{~mm}$, and mean annual temperature is $17.9^{\circ} \mathrm{C}$. The soil in this forest is classified as ferralic cambisol in USDA Soil Taxonomy.

Experimental nitrogen (N) addition was conducted in 2011 using a complete randomized block design. Three fertilization treatments, with three replicate plots for each treatment were used: without $\mathrm{N}$ addition $(\mathrm{CK})$, low- $\mathrm{N}$ treatment $(\mathrm{N} 1: 50 \mathrm{~kg} \mathrm{~N}$ $\left.\mathrm{ha}^{-1} \mathrm{yr}^{-1}\right)$, high $\mathrm{N}$ treatment $\left(\mathrm{N} 2: 100 \mathrm{~kg} \mathrm{~N} \mathrm{ha}^{-1} \mathrm{yr}^{-1}\right)$. Each plot was $20 \mathrm{~m} \times 20 \mathrm{~m}$ in size with $10 \mathrm{~m}$ buffer zone between plots. $\mathrm{N}$ was applied as $\mathrm{NH}_{4} \mathrm{NO}_{3}$. The $\mathrm{N}$ fertilizer was dissolved in $20 \mathrm{~L}$ water and sprayed evenly onto the plots. The CK plots received the same amount of water.

\section{Soil sampling and properties analysis}

Soil samples were collected in November 2019. At each replicate plot, five random samples from the surface soil were homogenized as one composite sample. All soil samples were passed through a 2-mm sieve and divided into two parts: one was air-dried for soil properties analysis; the other was stored at $-80{ }^{\circ} \mathrm{C}$. Soil $\mathrm{pH}$ was measured in a 1:2.5 dilution with deionized water using a $\mathrm{pH}$ meter. Soil total $\mathrm{N}$ (TN) was measured using an Elemental Analyzer (Elementar Vario EL III, Germany). Soil $\mathrm{NH}_{4}{ }^{+}-\mathrm{N}$ and $\mathrm{NO}_{3}^{-}-\mathrm{N}$ concentrations were determined with a continuous flow analyzer $\left(\mathrm{SAN}^{++}\right.$, Skalar, Holland) after extraction with $2 \mathrm{M} \mathrm{KCl}$. Dissolved organic carbon (DOC) was extracted 
with $0.5 \mathrm{M} \mathrm{K}_{2} \mathrm{SO}_{4}$ and measured using a Shimadzu TOC-5000 analyzer (Shimadzu, Kyoto, Japan). Total phosphorus (TP) was measured using the molybdenum method after digestion with $\mathrm{H}_{2} \mathrm{SO}_{4}-\mathrm{HClO}_{4}$.

\section{DNA extraction, fungal ITS gene amplification and sequencing}

Nucleic acid DNA was extracted from $0.25 \mathrm{~g}$ fresh soil with a DNeasy PowerSoil Pro Kit (QIAGEN, Germany) according to the manufacturer's protocol. The DNA concentration and quality were determined with a NanoDrop 2000 (Thermo), and the DNA was stored at $-80{ }^{\circ} \mathrm{C}$.

Fungal diversity and community composition were evaluated by amplicon sequencing of the fungal ITS1 region using tagged primer pairs ITS1F $\left(5^{\prime}-\right.$ CTTGGTCATTTAGAGGAAGTAA-3') /ITS2 (5'- GCTGCGTTCTTCATCGATGC3'), as described in Zhou et al. (2016). The PCR mixture $(50 \mu \mathrm{L})$ included $25 \mu \mathrm{l}$ of $2 \times$ Premix Ex TaqTM, $1 \mu \mathrm{M}$ of each primer, and $2 \mu \mathrm{L}$ of template DNA. The PCR conditions were as follows: $95{ }^{\circ} \mathrm{C}$ for $3 \mathrm{~min} ; 35$ cycles at $95{ }^{\circ} \mathrm{C}$ for $30 \mathrm{~s}, 55^{\circ} \mathrm{C}$ for $45 \mathrm{~s}$, $72{ }^{\circ} \mathrm{C}$ for $45 \mathrm{~s} ; 72^{\circ} \mathrm{C}$ for $6 \mathrm{~min}$. The PCR products were separated with $1.5 \%$ agarose gel and purified with gel extraction kits (QIAGEN, Germany) according to manufacturer's protocol. Purified PCR products were pyrosequenced on the Miseq PE250 platform (Illumina, San Diego, CA, USA) at Majorbio, Shanghai, China. Sequencing reads were processed with Mothur version 1.31.1 (Schloss et al., 2009). Trimmed sequences were grouped into operational taxonomic units (OTUs) at 97\% identity. Fungal alpha diversity was estimated by calculating the observed OTU numbers, ACE, Chao1, and Shannon values. All sequencing data has been uploaded to the NCBI Sequence Read Archive (SRA) database under accession number SRR9051171-SRR9051179.

\section{Statistical analysis}

Statistical analysis was conducted with SPSS 20.0 software (SPSS Inc., Chicago, IL, USA). One-way ANOVAs were conducted to assess the effects of different rates of $\mathrm{N}$ addition on soil properties, fungal alpha diversity, and abundant phyla and classes. Spearman's correlation analysis was performed to assess the correlations between soil properties and fungal alpha diversity and abundant phyla. Canonical correspondence analysis (CCA) and variation partitioning analysis (VPA) were used to investigate the impacts of abiotic factors on fungal community composition. Principal Coordinate Analysis (PCoA) based on Bray-Curtis distance matrices was performed to evaluate the fungal community similarity.

\section{Results}

\section{Effects of $N$ addition on soil properties}

Physicochemical properties were measured for the soil samples collected from different $\mathrm{N}$ addition treatments (i.e. CK, N1, and N2). Soil pH in N1 (4.40) and N2 (4.41) treatments were lower than $\mathrm{CK}$ (4.71) treatment (Figure 1). $\mathrm{N}$ addition enhanced soil nutrient content including $\mathrm{NH}_{4}{ }^{+}-\mathrm{N}, \mathrm{NO}_{3}{ }^{-}-\mathrm{N}, \mathrm{TN}$, and DOC, compared with $\mathrm{CK}$ treatment. The $\mathrm{NH}_{4}{ }^{+}-\mathrm{N}, \mathrm{NO}_{3}{ }^{-}-\mathrm{N}$, and DOC concentrations in the $\mathrm{N} 2$ treatment were similar with $\mathrm{N} 1$ treatment. However, no significant difference in TP was observed between $\mathrm{N}$ addition treatments and the CK treatment. 

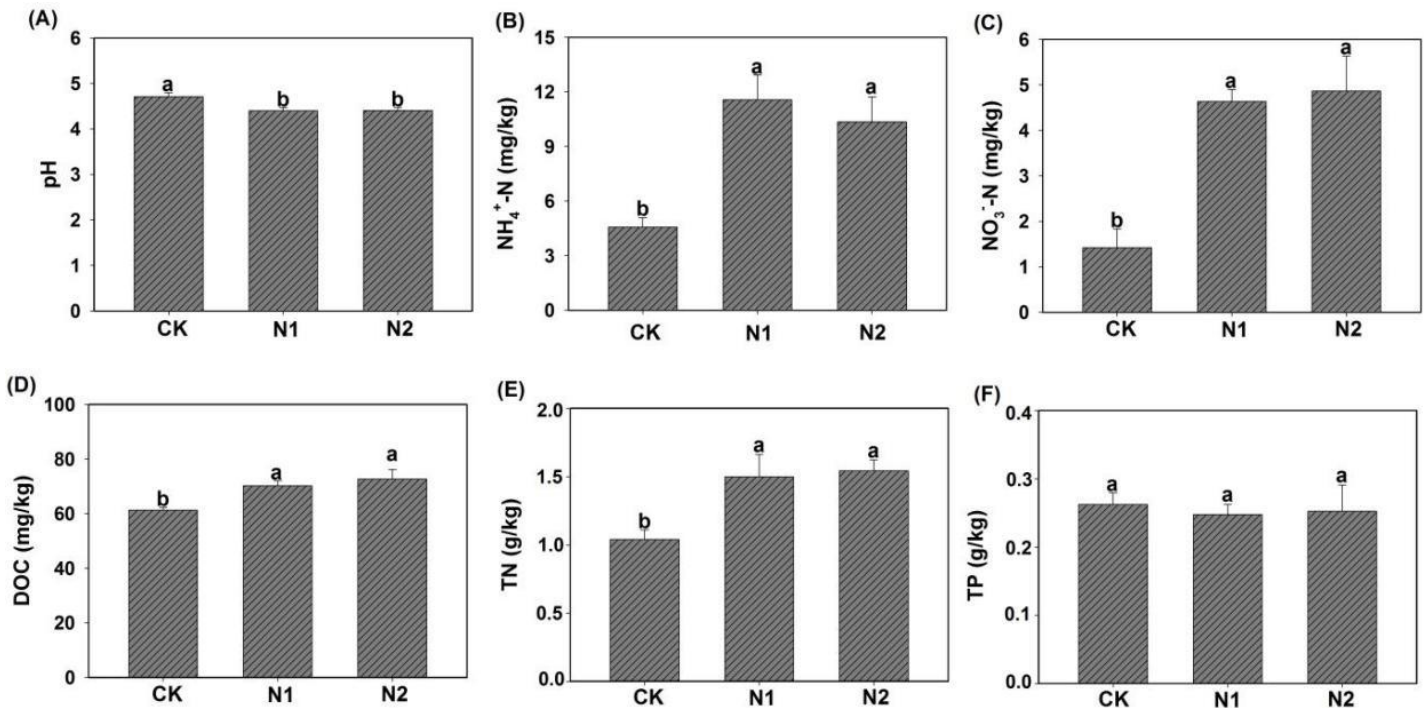

Figure 1. Effects of $N$ addition on soil properties. Values are mean \pm standard errors $(n=3)$. $\mathrm{NH}_{4}{ }^{+}-\mathrm{N}$ : ammonium-N; $\mathrm{NO}_{3}{ }^{-} \mathrm{N}$ : nitrate- $\mathrm{N}$; DOC: dissolved organic carbon; TN: total nitrogen; TP: total phosphorus. Different letters indicate significant differences among $N$ fertilizer treatments $(P<0.05)$

\section{Fungal alpha diversity}

There were significant differences in fungal richness and diversity $(\mathrm{P}<0.05)$ for observed OTU numbers, ACE, Chao1, and Shannon indices, but not significant differences in coverage (Table 1). Good's coverage values were around 99\%, indicating that the current numbers of sequence reads were enough to estimate the fungal diversity for these soil samples. The observed OTU numbers in the 9 soil samples ranged between 318 and 448. The ACE and Chao1 indices were measured to assess the fungal richness, and the Shannon index was used to assess fungal diversity. Compared with CK treatment, $\mathrm{N}$ addition significantly decreased observed OTU numbers, ACE, Chao1 richness, and Shannon diversity indices of the fungal community. However, no significant differences of alpha diversity indices were observed between $\mathrm{N} 1$ and $\mathrm{N} 2$ treatments (Table 2). Observed OTU numbers, Chao1, and Shannon indices were positively correlated with soil $\mathrm{pH}(\mathrm{P}<0.05)$ but negatively correlated with $\mathrm{NH}_{4}{ }^{+}-\mathrm{N}, \mathrm{NO}_{3}{ }^{-}-\mathrm{N}$, and $\mathrm{DOC}$ concentrations $(\mathrm{P}<0.05)$.

Table 1. Effects of $N$ addition on soil fungal alpha diversity

\begin{tabular}{c|c|c|c|c|c}
\hline \multirow{2}{*}{ Treatments } & \multirow{2}{*}{ Coverage } & \multirow{2}{*}{$\begin{array}{c}\text { Observed OTU } \\
\text { numbes }^{2}\end{array}$} & \multicolumn{2}{|c|}{ Richness } & Diversity \\
\cline { 3 - 5 } & & ACE & Chao1 & Shannon \\
\hline CK & $0.99 \pm 0.004 \mathrm{a}$ & $448 \pm 134 \mathrm{a}$ & $811 \pm 93 \mathrm{a}$ & $868 \pm 47 \mathrm{a}$ & $3.78 \pm 0.14 \mathrm{a}$ \\
N1 & $0.99 \pm 0.003 \mathrm{a}$ & $318 \pm 41 \mathrm{~b}$ & $641 \pm 82 \mathrm{~b}$ & $503 \pm 51 \mathrm{~b}$ & $2.97 \pm 0.06 \mathrm{~b}$ \\
N2 & $0.99 \pm 0.005 \mathrm{a}$ & $367 \pm 54 \mathrm{~b}$ & $631 \pm 85 \mathrm{~b}$ & $572 \pm 56 \mathrm{~b}$ & $2.54 \pm 0.31 \mathrm{c}$ \\
\hline
\end{tabular}

Values are mean \pm standard errors $(n=3)$. Different letters indicate significant differences among $\mathrm{N}$ fertilizer treatments at the 0.05 level. CK:without $\mathrm{N}$ addition; N1: low N addition; N2: high N addition 
Table 2. Spearman correlation between fungal alpha diversity and soil properties

\begin{tabular}{c|c|c|c|c}
\hline Soil properties & Observed OTU numbers & ACE & Chao1 & Shannon \\
\hline pH & $0.752^{*}$ & 0.581 & $0.772 *$ & $0.828 * *$ \\
$\mathbf{N H}_{4}^{+}-\mathbf{N}$ & $-0.862^{* *}$ & -0.509 & $-0.902 * * *$ & $-0.859 * *$ \\
$\mathbf{N O}_{3}^{-}-\mathbf{N}$ & $-0.882^{* *}$ & -0.628 & $-0.934 * * *$ & $-0.871 * *$ \\
DOC & $-0.735^{*}$ & -0.605 & $-0.737 *$ & $-0.817 * *$ \\
TN & -0.487 & -0.482 & -0.529 & $-0.840 * *$ \\
TP & 0.239 & -0.295 & 0.349 & 0.156 \\
\hline
\end{tabular}

$\mathrm{NH}_{4}{ }^{+}-\mathrm{N}$ : ammonium-N; $\mathrm{NO}_{3}{ }^{-}-\mathrm{N}$ : nitrate-N; DOC: dissolved organic carbon; TN: total nitrogen; TP: total phosphorus. $*, * *$, and $* * *$ were significantly correlated at $0.05,0.01$, and 0.001 levels, respectively

\section{Effects of $N$ addition on fungal community composition}

To investigate how $\mathrm{N}$ addition influenced fungal community structure, we performed PCoA based on Bray-Curtis distance matrices (Figure 2). The first two principal coordinates represented $46.83 \%$ (PCo1) and $23.57 \%$ (PCo2) of the total variation in fungal community, respectively. The PCoA analysis also revealed that $\mathrm{N}$ addition significantly changed fungal community structure separating it into three groups: CK, N1, N2.

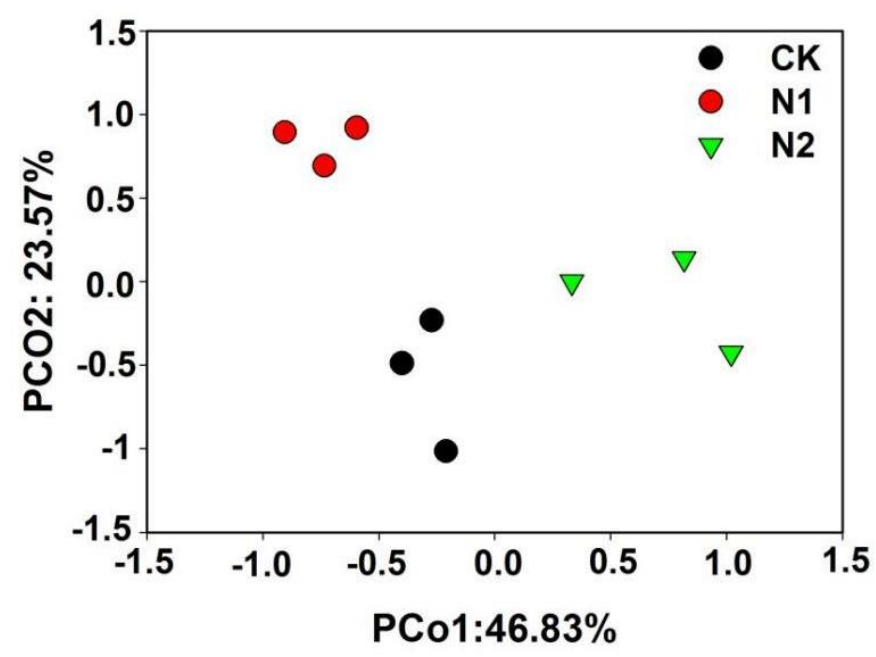

Figure 2. Principle coordinate analysis (PCoA) of fungal community structure among different $N$ addition treatments. $C K$ : without fertilizer; N1: low $N$ addition; N2: high $N$ addition

Ascomycota (29.53-60.10\%), Basidiomycota (25.93-54.12\%), and Zygomycota (2.41-10.74\%) were the predominant phyla in all soil samples (Figure $3 A$ ). N addition significantly altered the relative abundance of the main phyla ( $>1 \%$ relative abundance). The relative abundance of Ascomycota increased in the all $\mathrm{N}$ addition treatments, while Basidiomycota decreased compared to CK treatments (Figure 3A). However, the relative abundance of Zygomycota only increased in the high $\mathrm{N}$ addition (N2).

There were significant differences between fertilizer treatments at the class level of taxonomic classifications (Figure 3B). At the class level, six abundant classes were identified in soil samples, and $\mathrm{N}$ addition showed significant effects on them. The relative abundance of Agaricomycetes decreased in the $\mathrm{N}$ addition treatments, while the relative 
abundance of Sordariomycetes increased. However, the relative abundances of Dothideomycetes, Eurotiomycetes, and Incertae_sedis only increased in the N2 treatment. No significant differences in Leotiomycetes were observed among treatments.
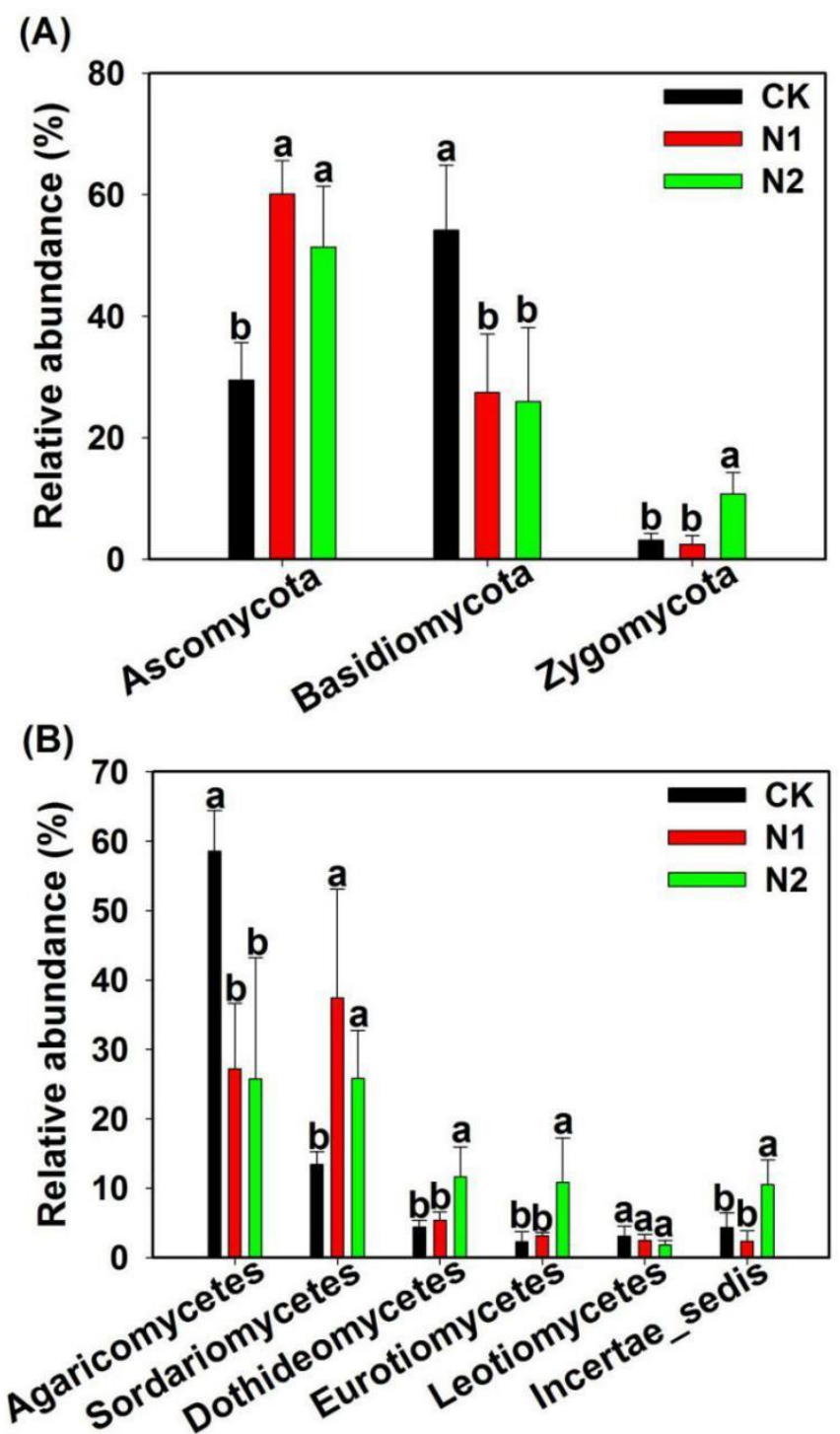

Figure 3. Relative abundances of the most abundant phyla and classes among the different $N$ addition treatments. Values are mean \pm standard errors $(n=3)$. Different letters indicate significant differences among $N$ fertilizer treatments at the 0.05 level. $C K$ : without fertilizer;

N1: low $N$ addition; $N 2$ : high $N$ addition

\section{Relationships between fungal community composition and soil properties}

The CCA showed that soil variables together explained $55.80 \%$ of the variations in fungal community structure, with the first two axes explaining $38.78 \%$ and $17.02 \%$ of variation, respectively (Figure 4). The fungal communities in the CK treatment were separated from the low (N1) and high N (N2) treatments along the first axis. The fungal community structure of the $\mathrm{CK}$ treatment was closely correlated with soil $\mathrm{pH}$. The fungal community structure of $\mathrm{N} 1$ and $\mathrm{N} 2$ treatments were significantly affected by $\mathrm{NH}_{4}{ }^{+}-\mathrm{N}$, 
$\mathrm{NO}_{3}{ }^{-}-\mathrm{N}$, and DOC. The CCA-based VPA was conducted to quantify the relative contribution of soil properties $\left(\mathrm{pH}, \mathrm{NH}_{4}{ }^{+}-\mathrm{N}, \mathrm{NO}_{3}{ }^{-}-\mathrm{N}\right.$, and DOC) on fungal community structure. $\mathrm{NH}_{4}{ }^{+}-\mathrm{N}$ and $\mathrm{NO}_{3}-\mathrm{N}$ together (23.17\%) explained more variation than $\mathrm{pH}$ $(8.18 \%)$ and DOC (5.28\%) (Figure 5). Interactions between available $\mathrm{N}$ and $\mathrm{pH}$ accounted for $3.02 \%$ of the variation, which were stronger than the interactions between available $\mathrm{N}$ and DOC (0.29\%) or $\mathrm{pH}$ and DOC (-0.1\%).

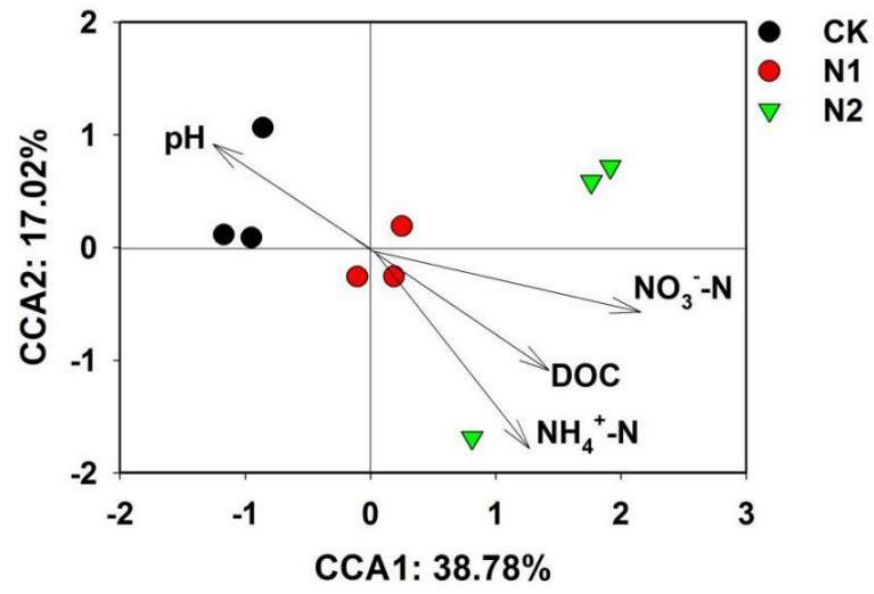

Figure 4. Canonical correspondence analysis (CCA) of fungal community structure among different $\mathrm{N}$ addition treatments. $\mathrm{NH}_{4}{ }^{+}-\mathrm{N}$ : ammonium- $\mathrm{N} ; \mathrm{NO}_{3}{ }^{-} \mathrm{N}$ : nitrate- $\mathrm{N} ; \mathrm{DOC}$ : dissolved organic carbon. CK: without fertilizer; N1: low $N$ addition; $N 2$ : high $N$ addition

\section{VPA}

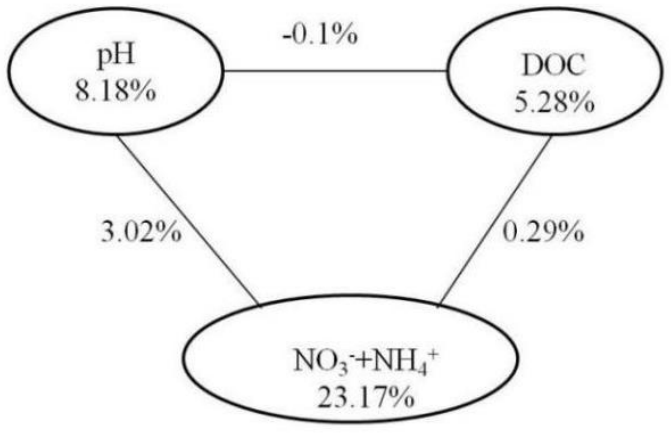

Unexplained $44.20 \%$

Figure 5. Variation partitioning analysis (VPA) of fungal community composition explained by soil chemical parameters. $\mathrm{NH}_{4}{ }^{+}-\mathrm{N}$ : ammonium-N; $\mathrm{NO}_{3}{ }^{-}-\mathrm{N}$ : nitrate- $\mathrm{N}$; DOC: dissolved organic carbon

Spearman's correlation coefficients were used to evaluate the relationships between abundant phyla and soil properties (Table 3). Most major phyla were significantly correlated with some soil properties, while only Zygomycota was not significantly correlated with any soil properties. The relative abundance of Ascomycota was negatively 
correlated with soil $\mathrm{pH}$ and positively correlated with $\mathrm{NH}_{4}{ }^{+}-\mathrm{N}, \mathrm{NO}_{3}^{-}-\mathrm{N}$, and DOC. In contrast, the relative abundance of Basidiomycota was positively correlated with soil $\mathrm{pH}$ and negatively correlated with $\mathrm{NH}_{4}{ }^{+}-\mathrm{N}, \mathrm{NO}_{3}{ }^{-}-\mathrm{N}$, and DOC.

Table 3. Spearman correlation coefficients between abundant phyla and soil properties

\begin{tabular}{c|c|c|c|c|c|c}
\hline & $\mathbf{p H}$ & $\mathbf{N H}_{4}{ }^{+}-\mathbf{N}$ & $\mathbf{N O}_{3}^{-}-\mathbf{N}$ & $\mathbf{D O C}$ & $\mathbf{T N}$ & $\mathbf{T P}$ \\
\hline Ascomycota & $-0.689^{*}$ & $0.843^{* *}$ & $0.838^{* *}$ & $0.678^{*}$ & 0.459 & -0.318 \\
Basidiomycota & $0.754 *$ & $-0.804 * *$ & $-0.844 * *$ & $-0.694^{*}$ & -0.653 & 0.293 \\
Zygomycota & -0.486 & 0.399 & 0.353 & 0.515 & 0.414 & -0.124 \\
\hline
\end{tabular}

$\mathrm{NH}_{4}{ }^{+}-\mathrm{N}$ : ammonium-N; $\mathrm{NO}_{3}{ }^{-}-\mathrm{N}$ : nitrate-N; DOC: dissolved organic carbon; $\mathrm{TN}$ : total nitrogen; $\mathrm{TP}$ : total phosphorus. $* \mathrm{P}<0.05, * * \mathrm{P}<0.01, * * * \mathrm{P}<0.001$

\section{Discussion}

After eight years of $\mathrm{N}$ fertilizer application, soil properties significantly shifted. $\mathrm{N}$ addition accelerated soil acidification leading to a lower $\mathrm{pH}$ value compared with the control treatment, which was comparable to previous studies (Lu et al., 2014; Cui et al., 2017; Li et al., 2019; Zhao et al., 2020). N addition enhanced soil nutrient concentrations of $\mathrm{NH}_{4}{ }^{+}-\mathrm{N}, \mathrm{NO}_{3}{ }^{-}-\mathrm{N}$, DOC. Dai et al. (2018) recently reported that $\mathrm{N}$ fertilization increased organic carbon and available $\mathrm{N}\left(\mathrm{NH}_{4}{ }^{-}-\mathrm{N}, \mathrm{NO}_{3}{ }^{-}-\mathrm{N}\right)$ content from a meta-analysis of a global dataset, which we corroborate here. In addition, fungal alpha diversity was also influenced by $\mathrm{N}$ addition. $\mathrm{N}$ additions in the present study caused lower fungal richness and diversity, which was consistent with previous studies (Allison et al., 2007; Zhou et al., 2016).

However, our results are inconsistent with the results of previous studies in forest ecosystems ( $\mathrm{Li}$ et al., 2019; Zhao et al., 2020). The response of fungal diversity to $\mathrm{N}$ inputs is not always consistent as a result of ecosystem type and nutrient availability (Allison et al., 2007; Chen et al., 2019; Li et al., 2019). $\mathrm{N}$ addition has been shown to lead to an increase in fungal richness and diversity in a low fertility boreal forest (Yan et al., 2017), while other studies found that $\mathrm{N}$ additions decreased fungal richness and diversity in grasslands (Chen et al., 2018a) and arable soil (Zhou et al., 2016). Moreover, Li et al. (2019) recently showed that $\mathrm{N}$ addition did not significantly alter fungal richness and diversity in a deciduous oak mixed forest. We show that $\mathrm{N}$ addition induced changes in soil $\mathrm{N}$ availability and was a key factor in influencing soil fungal alpha diversity, similar to Chen et al. (2018a). The direct impact of mineral $\mathrm{N}$ availability drove fungal richness and diversity changes in this fir plantation soil.

Fungal community structure was dramatically changed by the $\mathrm{N}$ addition treatments, consistent with previous studies (Bradley et al., 2006; Zhou et al., 2016; Li et al., 2019). Soil available $\mathrm{N}$ content had significant and positive relationships with fungal community structure. Soil $\mathrm{N}$ availability has consistently been identified as the key factor shaping microbial communities (Wang et al., 2017; Nie et al., 2018; Wang et al., 2018a).

Ascomycota, Basdiomycota, and Zygomycota were the most abundant phyla in all soil samples. Ascomycota and Basdiomycota are two very abundant fungal phyla in forest soils (Brown and Jumpponen, 2014; Li et al., 2019), which is consistent with our study. The relative abundance of Ascomycota increased after $\mathrm{N}$ fertilization, while Basidiomycota decreased, was similar to Zhou et al. (2016). Previous studies indicated that $\mathrm{N}$ addition significantly increased the relative abundance of copiotrophic phyla 
Ascomycota and reduced that of oligotrophic phyla Basidiomycota according to the copiotroph-oligotroph theory (Yao et al., 2017; Chen et al., 2018b). The relative abundances of Ascomycota and Basidiomycota were significantly correlated with soil $\mathrm{N}$ availability, suggesting that $\mathrm{N}$ addition may directly influence Ascomycota and Basidiomycota. Overall, $\mathrm{N}$ addition-induced changes in mineral $\mathrm{N}$ availability were the predominant drivers of fungal communities under simulated $\mathrm{N}$ treatments in a subtropical fir forest ecosystem.

\section{Conclusions}

After an eight years experimental $\mathrm{N}$ addition in a subtropical fir plantation, soil nutrient content increased and soil $\mathrm{pH}$ decreased. The $\mathrm{N}$ addition also decreased fungal species richness and biodiversity and led to substantial changes in fungal community structure. CCA and VPA analyses showed that soil $\mathrm{N}$ availability and soil $\mathrm{pH}$ changed significantly, and the $\mathrm{N}$ addition played a pivotal role in shaping fungal biodiversity and community composition. These results provide important information for identifying the main factors assembling fungal communities in subtropical forest ecosystems. Future research should take leaf litter and seasonal variations in order to better realize the response of fungal community to stimulate $\mathrm{N}$ deposition.

Acknowledgement. This work was supported by Academician Innovation Team Project (No. RZ2000008513KY).

\section{REFERENCES}

[1] Aguilar-Trigueros, C. A., Powell, J. R., Anderson, I. C., Antonovics, J., Rillig, M. C. (2014): Ecological understanding of root-infecting fungi using trait-based approaches. Trends in Plant Science 19: 432-438.

[2] Allison, S. D., Hanson, C. A., Treseder, K. K. (2007): Nitrogen fertilization reduces diversity and alters community structure of active fungi in boreal ecosystems. - Soil Biology and Biochemistry 39: 1878-1887.

[3] Altieri, M. A. (1999): The ecological role of biodiversity in agroecosystems. - Agriculture Ecosystem and Environment 74: 19-31.

[4] Bradley, K., Drijber, R. A., Knops, J. (2006): Increased N availability in grassland soils modifies their microbial communities and decreases the abundance of arbuscular mycorrhizal fungi. - Soil Biology and Biochemistry 38: 1583-1595.

[5] Brown, S. P., Jumpponen, A. (2014): Contrasting primary successional trajectories of fungi and bacteria in retreating glacier soils. - Molecular Ecology 23: 481-497.

[6] Canfield, D. E., Glazer, A. N., Falkowski, P. G. (2010): The Evolution and Future of Earth's Nitrogen Cycle. - Science 330: 192-196.

[7] Chen, W. Q., Xu, R., Chen, J., Yuan, X. P., Zhou, L., Tan, T. Y., Fan, J., Zhang, Y., Hu, T. M. (2018a): Consistent responses of surface- and subsurface soil fungal diversity to $\mathrm{N}$ enrichment are mediated differently by acidification and plant community in a semi-arid grassland. - Soil Biology and Biochemistry 127: 110-119.

[8] Chen, W. Q., Xu, R., Chen, J., Zhang, Y., Hu, T. M., Yuan, X. P., Zhou, L., Tan, T. Y., Fan, J. (2018b): Plant diversity is coupled with beta not alpha diversity of soil fungal communities following $\mathrm{N}$ enrichment in a semi-arid grassland. - Soil Biology and Biochemistry 116: 388-398. 
[9] Chen, D. M., Xing, W., Lan, Z. C., Saleem, M., Wu, Y. Q. Q., Hu, S. J., Bai, Y. F. (2019): Direct and indirect effects of nitrogen enrichment on soil organisms and carbon and nitrogen mineralization in a semi-arid grassland. - Functional Ecology 33(1): 175-187.

[10] Cui, J., Wang, J. J., Xu, J., Xu, C. H., Xu, X. N. (2017): Changes in soil bacterial communities in an evergreen broad-leaved forest in east China following 4 years of nitrogen addition. - Journal of Soils and Sediments 17: 2156.

[11] Dai, Z. M., Su, W. Q., Chen, H. H., Barberán, A., Zhao, H. C., Yu, M. J., Lu, Y., Brookes, P., Schadt, C. W., Chang, S. X., Xu, J. M. (2018): Long-term nitrogen fertilization decreases bacterial diversity and favors the growth of Actinobacteria and Proteobacteria in agro-ecosystems across the globe. - Global Change Biology 24(8): 3452-3461.

[12] Fierer, N., Lauber, C. L., Ramirez, K. S., Zaneveld, J., Bradford, M. A., Knight, R. (2012): Comparative metagenomic, phylogenetic and physiological analyses of soil microbial communities across nitrogen gradients. - The ISME Journal 6(5): 1007-1017.

[13] Galloway, J. N., Townsend, A. R., Erisman, J. W., Bekunda, M., Cai, Z., Freney, J. R., Martinelli, L. A., Seitzinger, S. P., Sutton, M. A. (2008): Transformation of the nitrogen cycle: recent trends, questions, and potential solutions. - Science 320: 889-892.

[14] He, D., Xiang, X. J., He, J. S., Wang, C., Cao, G. M., Adams, J. M., Chu, H. Y. (2016): Composition of the soil fungal community is more sensitive to phosphorus than nitrogen addition in the alpine meadow on the Qinghai-Tibetan Plateau. - Biology and Fertility of Soils 52(8): 1059-1072.

[15] Hooper, D. U., Adair, E. C., Cardinale, B. J., Byrnes, J. E. K., Hungate, B. A., Matulich, K. L., Gonzalez, A., Duffy, J. E., Gamfeldt, L., O'Connor, M. I. (2012): A global synthesis reveals biodiversity loss as a major driver of ecosystem change. - Nature 486(7401): 105108.

[16] IPCC (2007): Climate change 2007: the physical science basis. - In: Solomon, S., Qin, D., Manning, M. (eds.) Contribution of Working Group I to the Fourth Assessment Report of the Intergovernmental Panel on Climate Change. Cambridge: Cambridge University Press.

[17] IPCC (2017): Climate change 2017: the physical science basis. - In: Stocker, T. F., Qin, D., Plattner, G. K., Tignor, M., Allen, S. K., Boschung, J. (eds.) Contribution of Working Group I to the Fifth Assessment Report of the Intergovernmental Panel on Climate Change. Cambridge: Cambridge University Press.

[18] Isbell, F., Reich, P. B., Tilman, D., Hobbie, S. E., Polasky, S., Binder, S. (2013): Nutrient enrichment, biodiversity loss, and consequent declines in ecosystem productivity. Proceedings of the National Academy of Sciences of the United States of America 110(29): 11911-11916.

[19] Li, Y., Tian, D. S., Wang, J. S., Niu, S. L., Tian, J., Ha, D. L., Qu, Y. X., Jing, G. W., Kang, X. M., Song, B. (2019): Differential mechanisms underlying responses of soil bacterial and fungal communities to nitrogen and phosphorus inputs in a subtropical forest. - Peer J 7(6): e7631.

[20] Lu, X. K., Mo, J. M., Gilliam, F. S., Zhou, G. Y., Fang, Y. T. (2010): Effects of experimental nitrogen additions on plant diversity in an old-growth tropical forest. - Global Change Biology 16: 2688-2700.

[21] Lu, X. K., Mao, Q. G., Gilliam, F. S., Luo, Y. Q., Mo, J. M. (2014): Nitrogen deposition contributes to soil acidification in tropical ecosystems. - Global Change Biology 20(12): 3790-3801.

[22] Ma, B. B., Zhou, X. L., Zhang, Q., Qin, M. S., Hu, L. G., Yang, K. N., Xie, Z., Ma, W. B., Chen, B. B., Feng, H. Y., Liu, Y. J., Du, G. Z., Ma, X. J., Le Roux, X. (2019): How do soil micro-organisms respond to N, P and NP additions? Application of the ecological framework of (co-)limitation by multiple resources. - Journal of Ecology 107: 2329-2345.

[23] Morris, S. J., Blackwood, C. B. (2015): The ecology of the soil biota and their function. In: Eldor, E. A. (ed.) Soil Microbiology, Ecology and Biochemistry. 4th ed., Chap. 10, Cambridge, MA: Academic Press, pp. 273-309. 
[24] Nie, Y. X., Wang, M. C., Zhang, W., Ni, Z., Hashidoko, Y., Shen, W. J. (2018): Ammonium nitrogen content is a dominant predictor of bacterial community composition in an acidic forest soil with exogenous nitrogen enrichment. - Science of Total Environment 624: 407-415.

[25] Schloss, P. D., Westcott, S. L., Ryabin, T., Hall, J. R., Hartmann, M., Hollister, E. B. (2009): Introducing mothur: open-source, platform independent, community-supported software for describing and comparing microbial communities. - Applied and Environment Microbiology 75: 7537-7541.

[26] Wang, J. C., Song, Y., Ma, T. F., Raza, W., Li, J., Howland, J. G., Huang, Q. W., Shen, Q. R. (2017): Impacts of inorganic and organic fertilization treatments on bacterial and fungal communities in a paddy soil. - Applied Soil Ecology 112: 42-50.

[27] Wang, Q., Wang, C., Yu, W. W., Turak, A., Chen, D. W., Huang, Y., Ao, J. H., Jiang, Y., Huang, Z. R. (2018a): Effects of nitrogen and phosphorus inputs on soil bacterial abundance, diversity, and community composition in Chinese fir plantations. - Frontiers in Microbiology 9: 1543.

[28] Wang, Y., Ji, H. F., Hu, Y. X., Wang, R., Rui, J. P., Guo, S. L. (2018b): Different selectivity in fungal communities between manure and mineral fertilizers, a study in an alkaline soil after 30 years fertilization. - Frontiers in Microbiology 9: 2613.

[29] Wei, H., Peng, C. H., Yang, B., Song, H. X., Li, Q., Jiang, L., Wei, G., Wang, K. F., Wang, H., Liu, S. R., Liu, X. J., Chen, D. X., Li, Y. D., Wang, M. (2018): Contrasting soil bacterial community, diversity, and function in two forests in China. - Frontiers in Microbiology 9: 1693.

[30] Yan, G. Y., Xing, Y. J., Xu, L. J., Wang, J. Y., Dong, X. D., Shan, W. J., Guo, L., Wang, Q. G. (2017): Effects of different nitrogen additions on soil microbial communities in different seasons in a boreal forest. - Ecosphere 8(7): e01879.

[31] Yao, F., Yang, S., Wang, Z. R., Wang, X., Ye, J., Wang, X. G., DeBruyn, J. M., Feng, X., Jiang, Y., Li, H. (2017): Microbial taxa distribution is associated with ecological trophic cascades along an elevation gradient. - Frontiers in Microbiology 8: 2071.

[32] Zhao, A. H., Liu, L., Chen, B. D., Fu, W., Xie, W., Xu, T. L., Zhang, W., Ye, Q., Feng, H. Y., Fu, S. L. (2020): Soil fungal community is more sensitive to nitrogen deposition than increased rainfall in a mixed deciduous forest of China. - Soil Ecology Letters 2(1): 20-32.

[33] Zhou, J., Jiang, X., Zhou, B. K., Zhao, B. S., Ma, M. C., Guan, D. W., Li, J., Chen, S. F., Cao, F. M., Shen, D. L., Qin, J. (2016): Thirty-four years of nitrogen fertilization decreases fungal diversity and alters fungal community composition in black soil in northeast China. - Soil Biology and Biochemistry 95: 135-143. 